\title{
вмJ Global Health How to capture the individual and societal impacts of syndemics: the lived experience of COVID-19
}

\author{
Stefan Boes, ${ }^{1,2}$ Carla Sabariego, ${ }^{2,3}$ Jerome Bickenbach, ${ }^{2,3}$ Gerold Stucki ${ }^{2,3}$
}

To cite: Boes S, Sabariego C, Bickenbach J, et al. How to capture the individual and societal impacts of syndemics: the lived experience of COVID-19. BMJ Global Health 2021;6:e006735. doi:10.1136/ bmjgh-2021-006735

Handling editor Seye Abimbola

Received 29 June 2021

Accepted 8 October 2021
Check for updates

(C) Author(s) (or their employer(s)) 2021. Re-use permitted under CC BY-NC. No commercial re-use. See rights and permissions. Published by BMJ

${ }^{1}$ Department of Health Sciences and Medicine, University of Lucerne, Lucerne, Switzerland ${ }^{2}$ Center for Rehabilitation in Global Health Systems, WHO Collaborating Center, University of Lucerne, Lucerne, Switzerland

${ }^{3}$ Swiss Paraplegic Research, Nottwil, Switzerland

Correspondence to Professor Gerold Stucki; gerold.stucki@paraplegie.ch

\section{BACKGROUND}

To capture the complex interactions between health and social crises that he noticed in the HIV-AIDS pandemic, medical anthropologist Merrill Singer in the early 1990s invented the term syndemic to describe the "closely intertwined and mutual enhancing health problems that significantly affect the overall health status of a population'. 'Singer and Clair later expanded the notion to reconceptualise disease in a biosocial context, ${ }^{2}$ making the link to a systems approach to public health. Diseases, and especially highly infectious diseases that lead to pandemics, are never isolated assaults on the health of populations: they occur within a broader context characterised both by epidemiological patterns of other diseases and by social and economic factors that can dramatically affect transmission. Diseases themselves interact, creating disease clusters, and social and economic factors that affect disease dynamics are affected by them in turn. Conditions of social inequality-poverty, stigmatisation, stress and violence-play a role in disease exposure, and may dramatically increase vulnerability. Over the course of a pandemic, these same social conditions may also worsen. The value of syndemic thinking is that it 'brings together the environment and individual embodied experience to think about what types of interventions matter-from social policy to clinical practice'. ${ }^{4}$ In 2019, Lancet commissioned a report on the global syndemic of obesity that highlighted the 'multilayered and multidimensional array of factors implicated in the dramatic global rise of obesity, undernutrition and climate change'.

It should come as no surprise that we are now invited to view COVID-19 not as a pandemic but a syndemic. ${ }^{6}$ The characterisation fits what we know of the disease since both its spread and its lethality are strongly shaped by the impact of comorbid chronic health
Summary box

The notion of a 'syndemic' has recently been suggested as an apt description of the COVID-19 pandemic.

- A syndemic approach requires suitable causal models for disease interaction within the broader social and economic context, which poses a challenge for data collection.

- The WHO's International Classification of Functioning Disability and Health (ICF) is both a conceptual model for interactive relationships and a classification.

- The ICF provides an interaction model that can contribute to fulfilling the promise of a truly syndemic understanding of COVID-19.

problems, especially the non-communicable diseases of hypertension, obesity, diabetes, cardiovascular and chronic respiratory diseases, and cancers. ${ }^{7}$ There is also evidence that COVID-19 has a greater impact on social groups that experience greater social and economic inequality. ${ }^{8}$ Confirming the underlying hypothesis of syndemic theory, COVID-19 infection and mortality patterns have been shown to differ across countries and regions, and early evidence suggests that they depend at least to some extent on the social, political and economic context. In the USA, the Centers for Disease Control and Prevention researchers have shown differences in infection and mortality by racial and ethnic background, ${ }^{9}{ }^{10}$ and a recent study more broadly indicates that infection and mortality patterns reflect income inequality and its social consequences. ${ }^{11}$ Others have argued that the reverse may also be true: the spread of the disease and its economic impact will further worsen the inequalities in the USA and around the globe. ${ }^{12} 13$

Some have questioned not the syndemic framework itself, but the appropriate level of its application in the case of COVID-19. Emily Mendenhall, ${ }^{14}$ for example, argues 
persuasively that COVID-19 cannot be said to be a global syndemic because both the biological, but more importantly, the social and political drivers of the spread of the disease differ substantially between countries, and even between regions of countries. While there is a syndemic in the USA-because of its political failures to address racial and other disparities-it may not be correct to say there is a syndemic in, say, New Zealand where social factors are very different and less impactful on the spread of the disease. Whether the syndemic approach can only be applied locally has potential methodological consequences, as we shall see, but the general question of the value of the syndemic approach to understand COVID-19 as a global threat remains, as Mendenhall readily acknowledges.

Yet, even if calls for viewing COVID-19 as a syndemic may be well founded, the consequences for public health and clinical practice are not always clear. The claim that 'addressing COVID-19 means addressing hypertension, obesity, diabetes, cardiovascular and chronic respiratory diseases, and cancer ${ }^{6}$ is undoubtedly true but not very helpful in a social environment where public health measures, such as time-constrained lockdowns, have been politicised and made controversial. Potentially more useful is to pursue the insight that syndemics require a 'systems-thinking' approach, and that it is both naive, and ineffective, to reduce the social response to COVID-19 to the simple narrative of personal protective measures (PPM) (including the use of protective masks and physical distancing) and vaccination towards herd immunity, while ignoring the "context of the human host, its immune system, microbiome and economic, social and natural environment'. ${ }^{15}$ No doubt it is essential to appreciate the complexity of interacting factors in the prevention and response to COVID-19, as it is to recognise that society is a complex system that resists simplistic causal explanations. ${ }^{16}$ Yet even staunch proponents of the syndemic approach point to its Achilles' heel-the fact that 'the theory of syndemics has received scant empirical support either for its concept of disease interaction or for the model of mutually causal epidemics... [illustrating] important methodological gaps in the literature'. ${ }^{17}$

If finding suitable causal models for disease interaction-especially between communicable and noncommunicable diseases-is a methodological challenge, adding the broader societal context increases this challenge exponentially. Inasmuch as societies in general and health systems in particular are complex adaptive systems,${ }^{18}$ it is inevitable that a 'systems-thinking' approach will be required to operationalise the full consequences of syndemic insights, even if these are applied only in local situations. Any approach to realising the aspirations of the syndemic approach, in short, needs to be comprehensive, at least at the outset.

To begin with, it is important to be clear what the individual and societal impacts of COVID-19 are. Individually and socially, the most important impact is on mortality, which in the case of COVID-19 has reached 3.5 million global deaths at the time of writing. ${ }^{19}$ Disease morbidity, and its consequences, impacts both individuals and society. In addition, after the infection has been controlled there is increasing evidence of 'COVID-19 long hauling' (also referred to as post COVID-19 condition) characterised by a postrecovery persistence of 'rolling waves of symptoms' including fatigue, hallucinations, 'brain fog', delirium, memory loss, tachycardia, numbness and tingling, and shortness of breath. ${ }^{20}$

Through a syndemic lens, however, we need also to take into account the impact of the social response to the disease. A syndemic is thoroughly interactive, and both directions need equal attention. Countries worldwide have instituted basic public health measures such as masking, hygiene and distancing rules; others have gone further to put into effect far-reaching measures, such as travel restrictions, business and school closures, extended lockdowns, quarantines and curfews. Highresource countries are vaccinating at unprecedented rates (approaching 1.8 billion doses administered at the time of writing) ${ }^{19}$ although the pace for medium and low-resource countries is much slower and greatly depends on the capacity of wealthier countries to share their stocks of the vaccine. All of these measures aim to contain the spread of the virus, protect the most vulnerable groups of the population and prevent the collapse of healthcare facilities in light of overwhelming case numbers. Yet at the same time, many of the public health measures, and lockdowns and closures in particular, have had significant negative effects on societies and economies due to lost production and lower value added in affected business sectors, higher rates of unemployment, learning deficits and lost education, and physical and mental health consequences indirectly related to COVID19 , again with very different impacts depending on the social and economic context.

Taking all the synergetic impacts that constitute a syndemic into account-both as a matter of the lived experience of individuals, infected or indirectly affected by COVID-19, and the direct and indirect social and economic consequences of the disease-will require complex and interactive research frameworks and conceptual models, both quantitative and qualitative, and the systematic collection of reliable information. If we take the bold step of fully applying the syndemic approach, traditional epidemiological data and information on basic socioeconomic indicators may not be sufficient to comprehend the full extent of the impact of COVID-19. As Mendenhall and Singer have argued, ${ }^{14}$ the syndemic approach, initially shaped by ethnography, should continue to rely on nuanced anthropological and other qualitative methodologies. But what is particularly required is a broadly based, interdisciplinary and truly interactive conceptualisation of the individual experience of health and the societal response to the needs created by that experience.

The objective of this paper is to suggest that an appropriate conceptual model to guide the collection of 
relevant information capturing the syndemic interactions and resulting societal response is the WHO's International Classification of Functioning, Disability and Health (ICF). ${ }^{21}$ The ICF, we argue, can serve as an overall conceptual model for data collection that can be used as a reference framework for both quantitative and qualitative data collection efforts and is compatible with a wide range of data collection methodologies. Based on the interactive model of functioning, the ICF can serve as a reference framework for augmenting existing data in order to fully capture the extent and dimensions of the individual and societal impacts of COVID-19, and other syndemics. Moreover, as a classification, the ICF provides an international reporting system for syndemic information from whatever source.

\section{THE ICF AND THE SOCIAL IMPACT OF SYNDEMICS}

Although it was developed for several applications and use cases, and has since its endorsement by the World Health Assembly in 2001 been used for many purposes, the primary aim of the ICF was to augment WHO's International Classification of Diseases (ICD) to more fully capture information about health and the lived experience of health. ${ }^{22}$ In effect, WHO created, alongside mortality and morbidity, the third health indicator of 'functioning', expressly to capture the impact of an underlying health problem on the life of individuals in the actual context in which the individual lives, acts and participates in all areas of interpersonal and social life. ${ }^{23}$ The ICF, although primarily a classification, implicitly models the dimension of functioning as an outcome of multidimensional interactions between the intrinsic health state of a person and his or her actual physical, human-built, interpersonal, attitudinal, social, economic and political environment. Functioning, in short, is the lived experience of health, and problems in functioning or disability are what matter to people about their health state as they carry out their lives. ${ }^{24}$

COVID-19 is an infectious disease with widespread symptoms, sequelae and lethality, information about which is captured in the first instance by mortality and morbidity. Nonetheless, functioning information is required to better understand the impact of the virus on people's lives, during and after the infection, in case of persistent symptoms, and especially the impact of social, political and attitudinal determinants on the functioning of individuals in their daily lives. Taking full account of context, two persons with similar COVID-19 symptoms can have very different levels of functioning in their daily lives due to specificities of the physical, interpersonal, social and political environments in which they live.

The ICF offers both an interactive model and a reference classification to describe the full impact of COVID-19 on life, at the individual or population level, taking into account the environmental context in which persons live-from living conditions and personal relationships to social and economic factors. The underlying

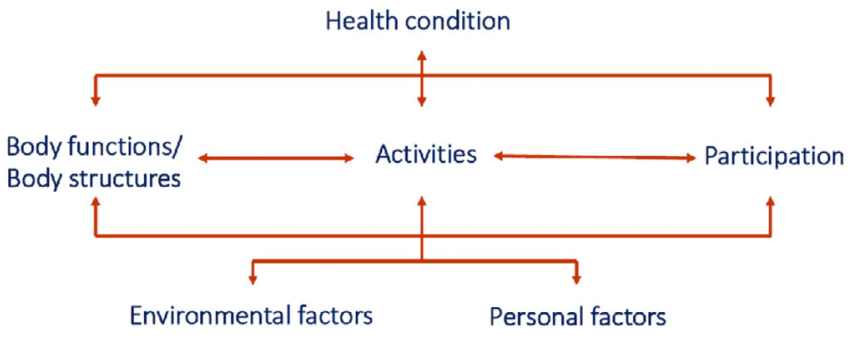

Figure 1 Graphical illustration of the conceptual model of WHO's International Classification of Functioning, Disability and Health (ICF).

conceptual model of the ICF (see figure 1) brings together the salient components of interactive process that creates both the individual's experience of health and the societal impact. The capacity of the ICF to fully describe the health state of an individual or a population, and the full context in which the person or population with specific health states live and act, as well as the interactions between individuals and the wider social context, makes it possible to capture the lived experience of a health condition such as COVID-19. Indeed, the ICF provides us with the syndemic picture of the disease from the individual perspective, used either in clinical routine or, from a population perspective, in health surveys, providing the foundation for data collection tools for both perspectives (see also table 1). The result is a kind of syndemic social lens through which the complex interactions that shape the trajectory of COVID-19 can be described and ultimately explained.

\section{COVID-19 AND HEALTH INDICATORS}

Mortality and infection rates of COVID-19 are statistics that rely on the standardised reporting of cases made possible by a common reference system of WHO's ICD. What is not reported so far in a standardised manner is how both those with infections and those who have recovered from the infection are functioning in their daily lives. We lack an enormous amount of information at the moment, information that will be needed to plan the medium-term and long-term responses of health systems to COVID-19, or possible future variants, including, for instance, the need of rehabilitation for full recovery. ${ }^{25}$

ICF is a conceptual model and classification framework for identifying and recording evidence on the lived experience of individuals from an interactive perspective, that is, fully taking into account the role played by their social, economic and political environments. The usefulness of ICF has been demonstrated especially in the context of rehabilitation. In order to better understand COVID-19, and to support full recoveries, we need to foster the identification and collection of functioning data-both clinical and environmental-as has been recently proposed by the International Society of Physical and Rehabilitation Medicine (ISPRM): using the ICF-based Clinical Functioning Information Tool (ClinFIT), a tool for health professionals who provide rehabilitation, as a starting 
Table 1 Overview of the Clinical Functioning Information Tool (ClinFIT) and the WHO and World Bank Model Disability Survey (MDS), both exemplary ICF-based instruments

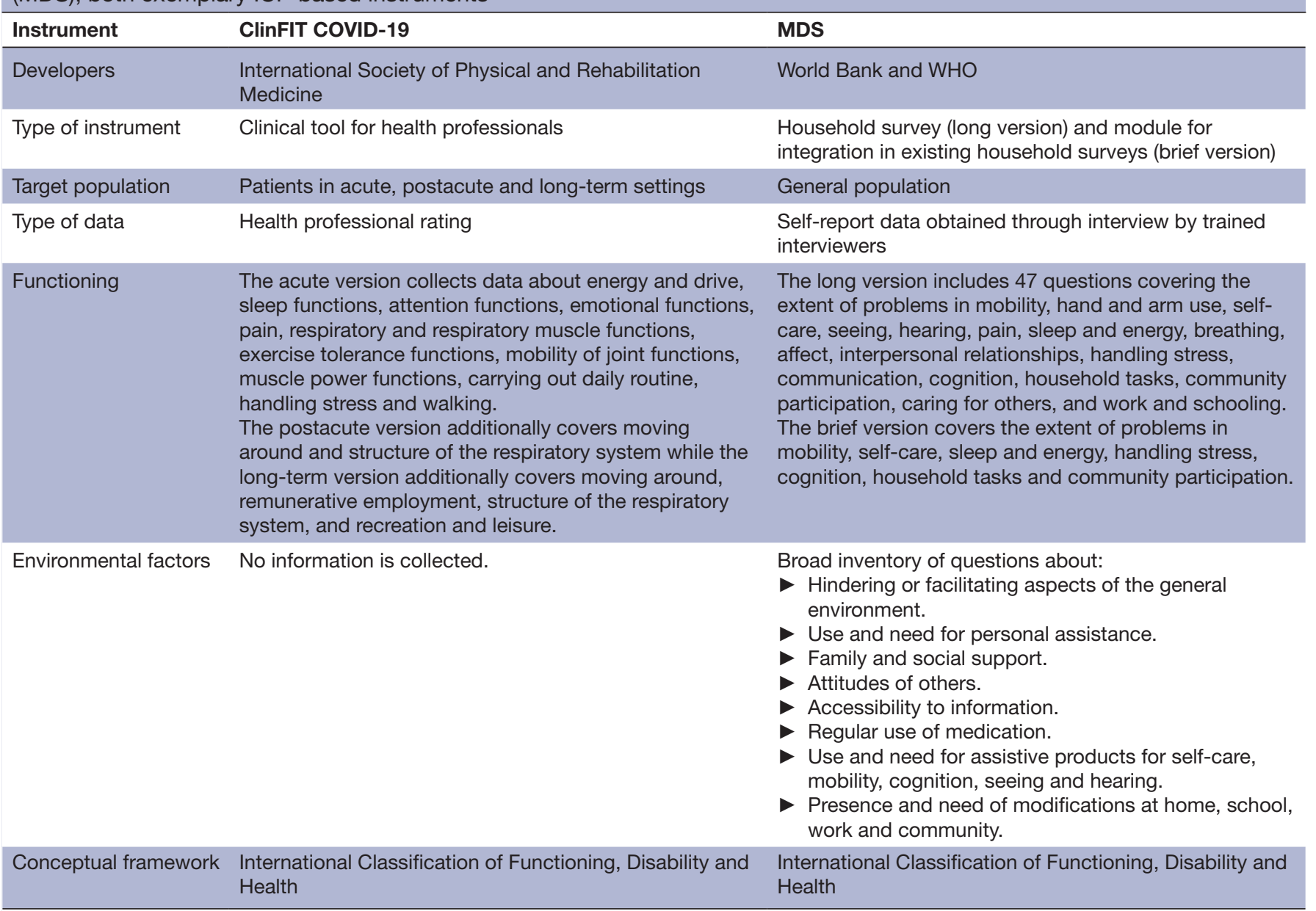

ICF, International Classification of Functioning, Disability and Health.

point, ISPRM developed a version suitable to capture the functioning of patients with COVID-19 during and after the infection. ${ }^{26}$

Given that so little was known about the pathogenesis and epidemiology of COVID-19 when early cases were reported out of China, it was reasonable that the social response was focused on short-term public health measures. Soon enough, however, the uncontrolled spread of this highly infectious disease was far reaching and very different from that of a non-communicable disease. ${ }^{27}$ In particular, we soon saw the need to take into account the middle-term and long-term social impacts of post COVID-19 condition as well as the impact of nonpharmaceutical interventions (NPIs) that societies have instituted in order to limit the spread of the disease. Applying the syndemic model, moreover, requires a comprehensive analysis of disease dynamics and social dynamics. In order to understand the complex interactions, both between COVID-19 and other health conditions and the social and economic responses to and impacts of the disease, and to better prepare countries and health systems for future challenges, we need to ensure that we collect data, at the population level, that fully capture all aspects of the syndemic model of the disease. Here, too, WHO's ICF is a useful framework: ICF models individual and population outcomes in terms of interactions between health states and social, cultural, economic and environmental factors and has served as basis for a full range of population surveys, such as the WHO and the World Bank Model Disability Survey (MDS) ${ }^{28}{ }^{29}$ In short, ICF can both support systematic data collection and reporting and guide the social response to COVID-19 that takes into account the bidirectional disease social impacts.

The issue of what to measure in the case of COVID-19 would ideally be a core set developed for COVID-19, in the pattern of existing core sets for ankylosing spondylitis, breast cancer and stroke.$^{30}$ However, in light of the urgency of the current pandemic, the ClinFIT COVID-19 tool, which can be used in acute, postacute and longterm settings and whose development followed a multistep process including a survey of ISPRM members worldwide, is the best starting point in terms of what to measure. ${ }^{31}$ Given the clinical character of ClinFIT COVID-19, it collects only essential information on body functions (energy and drive functions, sleep functions, attention functions, emotional functions, pain, respiratory functions, respiratory muscle functions, exercise 
tolerance functions, mobility of joint functions, muscle power functions), body structures (structure of the respiratory system) and on activities and participation domains (carrying out daily routine, handling stress and other psychological demands, walking, moving around, remunerative employment, recreation and leisure).

At the population level, a comprehensive ICF-based survey like the WHO and the World Bank MDS is suitable for generating an overall score of functioning with metrical properties, an indicator that can complement mortality and morbidity indicators by proving a measure of how COVID-19 impacts the functioning and health of individuals. Moreover, the MDS can support the identification of key social and economic determinants of the functioning of persons with or without COVID$19^{29}$ and the impact on the spread of the disease itself across the population. The MDS- the current standard recommended by WHO to assess functioning at population level-is a dedicated survey available online in two formats: a stand-alone comprehensive survey, including a large inventory of environmental factors, and a brief functioning module (brief MDS) for inclusion in household surveys. ${ }^{28}$ Since the brief MDS is concise and generates good overall scores of functioning, ${ }^{29}$ it might be a good choice for assessing functioning in the context of COVID-19 in the scope of routine household surveys.

Table 1 provides an overview of the ClinFIT COVID-19 tool and the MDS. However, we suggest broadening the scope of functioning surveys like the MDS to be more sensitive to the COVID-19 syndemic, especially regarding the role of social determinants and other environmental factors. For instance, it will be useful to include domains that capture access to PPMs, and to target more detailed information on, for instance, socioeconomic status, access to financial benefits and financial stability of households. ${ }^{32}$ This would account for the full consequences of NPIs, such as the impacts on employment and structural changes in the economy, lowering production, income and consumption. ${ }^{33-36}$ Other domains would detail specifics of the natural environment and community and civic life. Each domain considered needs to be evaluated in terms of both positive and negative socioeconomic impacts. For example, the imposed NPIs across countries might reduce air pollution due to the reduction of air travel, mobility and land transport, ${ }^{37}$ while at the same time less available income may increase the use of cheaper, less environmental friendly products, and fewer public resources may slow down investment in research and environmental protection. ${ }^{38}$ There are also concerns that strict NPIs such as curfews lead to increased domestic violence, ${ }^{39}$ although other types of crime may be less prevalent.

In order to include such macrolevel information into ICF-based surveys sensitive to the evaluation of a syndemic, the adaptation of indicators, such as those used by the Organisation for Economic Co-operation and Development ${ }^{40}$ or the World Bank, ${ }^{41}$ to self-report is appropriate. To allow for an evaluation of NPIs, standards such as the Oxford COVID-19 Government Response Tracker should be used from the perspective of the person. ${ }^{42}$ This stringency index should be complemented with information on the impact of government actions aiming to strengthen the economy, such as income support and debt relief for households, or other fiscal measures, as described, for example, by the International Monetary Fund or the International Labour Organization, on the survey respondent.

It is important to stress, however, that a fuller picture of a syndemic can only be created by more nuanced qualitative data from ethnographic, historical and other approaches. These can capture particular features of individual and social interactions, which may be unique to local conditions and not generalisable across countries. ${ }^{14}$ Although the ICF has been extensively used in epidemiology, health systems research and clinical practices, where the focus has been on quantitative information for measurement purposes, the ICF has been widely used for collecting and conceptualising qualitative information as well (see, eg, ref 43). As a classification, the ICF is neutral with respect to data collection technique (and it is constructed to accommodate highly granular information to be fit for purpose). As a conceptual model, moreover, the ICF sets out the most general of interactive person-environment models that are essentially theory neutral and are fully compatible with highly localised and specific ethnographic, sociological or historical research.

\section{CONCLUSION}

The ultimate goal of conceptualising the data requirements of a truly syndemic understanding of COVID-19, as a social lens for guiding policymaking and the development of effective and efficient public health measures, requires a sophisticated, interactive model that the ICF can provide. The ICF helps to identify the kinds of information that need to be collected-be it quantitative or qualitative-and in particular the range of functioning information that is as comprehensive as possible. At the individual level, ICF information can track the trajectories of post COVID-19 condition and other impacts of the disease. At the population level, functioning information is best reported using composite scores so that distributions for specific risk groups, aspects of socioeconomic status and other potential factors determining and characterising a syndemic can be quantitatively recorded over time and guide qualitatively research, in terms of what needs to be understood in depth.

Acknowledgements The authors would like to thank Cristiana Baffone for the support in the preparation of the manuscript.

Contributors All the authors wrote and reviewed the article.

Funding The authors have not declared a specific grant for this research from any funding agency in the public, commercial or not-for-profit sectors.

Competing interests None declared.

Patient and public involvement Patients and/or the public were not involved in the design, or conduct, or reporting, or dissemination plans of this research.

Patient consent for publication Not required. 
Provenance and peer review Not commissioned; externally peer reviewed.

Data availability statement There are no data in this work.

Open access This is an open access article distributed in accordance with the Creative Commons Attribution Non Commercial (CC BY-NC 4.0) license, which permits others to distribute, remix, adapt, build upon this work non-commercially, and license their derivative works on different terms, provided the original work is properly cited, appropriate credit is given, any changes made indicated, and the use is non-commercial. See: http://creativecommons.org/licenses/by-nc/4.0/.

\section{REFERENCES}

1 Singer M. A dose of drugs, a touch of violence, a case of AIDS: conceptualizing the SAVA syndemic. Free Inq Creative Sociol 1996;24:99-110

2 Singer M, Clair S. Syndemics and public health: reconceptualizing disease in bio-social context. Med Anthropol Q 2003;17:423-41.

3 Singer M. Introduction to syndemics: a systems approach to public and community health. San Francisco, CA: Jossey-Bass, 2009.

4 Mendenhall E, Singer M. What constitutes a syndemic? Methods, contexts, and framing from 2019. Curr Opin HIV AIDS 2020;15:213-7.

5 Swinburn BA, Kraak VI, Allender S, et al. The global syndemic of obesity, undernutrition, and climate change: the Lancet Commission report. Lancet 2019;393:791-846.

6 Horton R. Offline: COVID-19 is not a pandemic. Lancet 2020;396:874.

7 World Health Organization. COVID-19 clinical management. Living guidance, 2021. Available: https://www.who.int/publications/i/item/ WHO-2019-nCoV-clinical-2021-1 [Accessed 25 Jun 2021]

8 Oronce CIA, Scannell CA, Kawachi I, et al. Association between State-Level income inequality and COVID-19 cases and mortality in the USA. J Gen Intern Med 2020;35:2791-3.

9 Price-Haywood EG, Burton J, Fort D, et al. Hospitalization and mortality among black patients and white patients with Covid-19. N Engl J Med 2020;382:2534-43.

10 Centers for Disease Control and Prevention. Health equity considerations and racial and ethnic minority groups, 2021. Available: https://www.cdc.gov/coronavirus/2019-ncov/community/ health-equity/race-ethnicity.html [Accessed 25 Jun 2021].

11 Elgar FJ, Stefaniak A, Wohl MJA. The trouble with trust: time-series analysis of social capital, income inequality, and COVID-19 deaths in 84 countries. Soc Sci Med 2020;263:113365.

12 Dorn Avan, Cooney RE, Sabin ML. COVID-19 exacerbating inequalities in the US. Lancet 2020;395:1243-4.

13 Hill R, Narayan A. What COVID-19 can mean for long-term inequality in developing countries. Available: https://blogs.worldbank.org/ voices/what-covid-19-can-mean-long-term-inequality-developingcountries

14 Mendenhall E. The COVID-19 syndemic is not global: context matters. Lancet 2020;396:1731.

15 Klement RJ. Systems thinking about SARS-CoV-2. Front Public Health 2020;8:585229.

16 Bradley DT, Mansouri MA, Kee F, et al. A systems approach to preventing and responding to COVID-19. EClinicalMedicine 2020;21:100325.

17 Tsai AC, Mendenhall E, Trostle JA, et al. Co-occurring epidemics, syndemics, and population health. Lancet 2017;389:978-82.

18 Luke DA, Stamatakis KA. Systems science methods in public health: dynamics, networks, and agents. Annu Rev Public Health 2012;33:357-76.

19 World Health Organization. WHO coronavirus disease (COVID-19) Dashboard. Available: https://covid19.who.int [Accessed 7 May 2021].

20 Huang C, Huang L, Wang Y, et al. 6-month consequences of COVID-19 in patients discharged from hospital: a cohort study. Lancet 2021;397:220-32.

21 World Health Organization. International Classification of Functioning, Disability and Health, 2001. Available: https://www. who.int/standards/classifications/international-classification-offunctioning-disability-and-health [Accessed 7 May 2021].
22 Stucki G. Olle Höök Lectureship 2015: the World Health Organization's paradigm shift and implementation of the International Classification of Functioning, Disability and Health in rehabilitation. J Rehabil Med 2016-486-93.

23 Stucki G, Bickenbach J. Functioning: the third health indicator in the health system and the key indicator for rehabilitation. Eur J Phys Rehabil Med 2017;53:134-8.

24 Stucki G, Bickenbach J, Selb M. The International Classification of Functioning, Disability and Health. In: Frontera AR, DeLisa JA, Bockeneck W, eds. DeLisa's Physical Medicine and Rehabilitation Principles and Practice. $6^{\text {th }}$ ed. Philadelphia: Wolters Kluwer Medical, 2020: 208-26

25 Stam HJ, Stucki G, Bickenbach J, et al. Covid-19 and post intensive care syndrome: a call for action. J Rehabil Med 2020;52:jrm00044.

26 Developing ClinFIT COVID-19: an ISPRM initiative to scale up rehabilitation for COVID-19 patients and survivors across the care continuum. Available: https://www.isprm.org/survey-proposal-clinfitcovid-19/ [Accessed 25 Jun 2021].

27 Nicola M, Alsafi Z, Sohrabi C, et al. The socio-economic implications of the coronavirus pandemic (COVID-19): a review. Int J Surg 2020;78:185-93.

28 World Health Organization. Disability: model disability survey. Available: https://www.who.int/news-room/q-a-detail/modeldisability-survey [Accessed 25 Jun 2021].

29 Sabariego C, Fellinghauer C, Lee L. Measuring functioning and disability using household surveys: metric properties of the brief version of the who and world bank model disability survey. Arch Public Health 2021;79.

30 Bickenbach J, Cieza A, Selb M, eds. ICF Core Set: Manual for clinical proactice. $2^{\text {nd }}$ ed. Göttingen: Hogrefe Publishing, 2021.

31 International Society of Physical and Rehabilitation Medicine. Survey: proposal ClinFIT COVID-19. Available: https://www.isprm. org/survey-proposal-clinfit-covid-19/ [Accessed 25 Jun 2021].

32 Organisation for Economic Co-operation and Development. OECD guidelines for micro statistics on household wealth. OECD Publishing, 2013

33 Committee for the Coordination of Statistical Activities. How COVID-19 is changing the world: a statistical perspective. volume III, March 30, 2021. Committee for the coordination of statistical activities. Available: https://www.wto.org/english/tratop_e/covid19_ e/ccsa_publication_vol3_e.pdf [Accessed 25 June 2021].

34 Fana M, Tolan S, Torrejon Perez S. The COVID confinement measures and EU labour markets, EUR 30190 EN 30190 IT. Luxembourg: Publications office of the European Union, 2020.

35 International Labour Organization. ILO monitor: COVID-19 and the world of work. Seventh ed. International Labor Organization, 2021. https://www.ilo.org/wcmsp5/groups/public/@dgreports/@dcomm/ documents/briefingnote/wcms 767028.pdf

36 Remes J, Manyika J, Smit S. The consumer demand recovery and lasting effects of COVID-19. McKinsey Global Institute, 2021.

37 European Environment Agency. COVID-19 and Europe's environment: impacts of a global pandemic. European Environment Agency, 2020. Available: https://www.eea.europa.eu/publications/ covid-19-and-europe-s/covid-19-and-europes-environment [Accessed 25 Jun 2021].

38 Antoniades A, Widiarto I, Antonarakis AS. Financial crises and the attainment of the SDGs: an adjusted multidimensional poverty approach. Sustain Sci 2020;15:1683-98.

39 Evans ML, Lindauer M, Farrell ME. A Pandemic within a Pandemic - Intimate Partner Violence during Covid-19. N Engl J Med 2020;383:2302-4.

40 Organisation for Economic Co-operation and Development. OECD data. Available: https://data.oecd.org/searchresults/?r=+f/type/ indicators [Accessed 25 Jun 2021]

41 World Bank. World development indicators, world bank data Catalogue. the world bank group. Available: https://datacatalog. worldbank.org/dataset/world-development-indicators [Accessed 25 Jun 2021].

42 Hale T, Angrist N, Goldszmidt R, et al. A global panel database of pandemic policies (Oxford COVID-19 government response Tracker). Nat Hum Behav 2021;5:529-38.

43 Cieza A, Anczewska M, Ayuso-Mateos JL, et al. Understanding the Impact of Brain Disorders: Towards a 'Horizontal Epidemiology' of Psychosocial Difficulties and Their Determinants. PLoS One 2015;10:e0136271. 